\title{
Modos de articulación entre política y economía en el pensamiento de Aristóteles: divergencias con la hermenéutica arendtiana
}

\author{
Miguel Ángel Rossi \\ Universidad de Buenos Aires \\ mrossi@lorien-sistemas.com
}

\author{
HERNÁN BORISONIK \\ Universidad de Buenos Aires \\ hbori2@yahoo.com \\ ELENA MANCINELLI \\ Universidad de Buenos Aires \\ elenamancinelli@gmail.com
}

\begin{abstract}
Resumen: El objetivo de este artículo es reflexionar acerca de los modos en los que la política y la economía se articulan en la cosmovisión aristotélica. Para ello trabajaremos dos ejes temáticos. En primer lugar, la relación entre oíkos y polis y, en segundo lugar, la relación entre economía y los regímenes políticos. Uno de los aspectos nodales del trabajo gira en torno a mostrar nuestras diferencias con respecto a la hermenéutica de Arendt y, en tal sentido, el artículo hace énfasis en la importancia que también tiene para Aristóteles la dimensión económica para pensar la política, cuestión más que clara en el régimen que el Estagirita considera el mejor posible: la politeia.

Palabras clave: oíkos, polis, regímenes políticos, crematística
\end{abstract}

\begin{abstract}
The aim of this paper is to examine the ways in which politics and economy are articulated in the Aristotelian view. To achieve this end, two thematic axes are developed. First, the relationship between oikos and polis and, secondly, the relationship between economy and political regimes. One of the central features of this work is to show our differences with Arendt's hermeneutic. Thus, our paper emphasizes the importance of the economic dimension within Aristotle's political thought, even for thinking politics itself -an aspect that becomes clear in the constitution that Aristotle considered the best possible: the politeia.
\end{abstract}

Key words: oikos, polis, political regimes, chrematistics

\section{Introducción}

Toda reflexión acerca del pasado nos remite necesariamente a nuestro presente, sobre todo cuando aceptamos que lo clásico, lejos de evocarse como algo ahistórico, desencarnado de toda materialidad, constituye una inagotable fuente de la cual emana una pluralidad de sentidos que 
contribuyen a repensar nuestras propias encrucijadas. En tal sentido, Aristóteles es por antonomasia un pensador clásico, pues sus preocupaciones son un terreno fértil para la teoría y la ciencia política contemporáneas. De hecho, uno de los temas centrales del pensamiento político en la actualidad es la tensión entre política y economía, la cual nos retrotrae a los umbrales mismos de la polis griega. Al respecto, Aristóteles logró problematizar ese complejo vínculo con una intensidad que nos interpela hasta el día de hoy.

Asimismo, como bien lo señala Polanyi, ${ }^{1}$ el mundo clásico no careció de la organización de un sistema de satisfacción de necesidades que, en un sentido laxo, podríamos definir como economía. Lo cierto, sin embargo, es que ésta se subordinaba a la organización política y no a la inversa, como acontece en el capitalismo. No obstante, los griegos no fueron ajenos a la invención del dinero, aspecto sobre el cual el Estagirita se ocupó específicamente. Al respecto, es interesante reparar en una observación de Moreau, quien ha mostrado cómo la censura aristotélica gira en torno al mal uso del dinero, y no a su propia existencia:

Las perversiones económicas, denunciadas por Aristóteles, proceden de un uso desordenado de la moneda, considerada la forma fundamental de la riqueza, cuando no es sino un medio para el intercambio, una institución al servicio de fines humanos. ${ }^{2}$

Es en ese sentido en el que Aristóteles destaca la magnificencia (hacer un buen uso del dinero y de la propiedad) como una virtud fundamental de la polis. ${ }^{3}$ Scott Meikle muestra con mayor profundidad la paradoja que encierra el uso del dinero para Aristóteles, pues: "el dinero no puede abolirse, por lo que debe tener uso aceptable; pero causa daño, por lo que debe tener un uso inaceptable". ${ }^{4}$

${ }^{1}$ K. Polanyi, "Aristóteles descubre la economía", en K. Polanyi, C. Arensberg y H.W. Peason, Comercio y mercado en los imperios antiguos, trad. A. Nicolás y J. Martínez Alier, Labor, Barcelona, 1976, pp. 111-144.

${ }^{2}$ ['Les perversions économiques, dénoncées par Aristote, procèdent d'un usage déréglé de la monnaie, tenue pour la richesse fondamentale, alors qu'elle n'est qu'un moyen en vue de l'échange, une institution au service des fins humaines."] J. Moreau, "Aristote et la monnaie", Revue des Études Grecques, vol. 82, no. 2, 1969, pp. 349-364; la cita es de la p. 363.

${ }^{3}$ Acerca de la arbitrariedad del dinero o del uso del dinero véase Ética nicomáquea 1133a; Política 1257b. Sobre la propiedad en relación con el negocio y el placer, véase Ética nicomáquea 1095b; Política 1258a.

${ }^{4}$ ["Money cannot be abolished so there had better be an acceptable use of it, 
Por otro lado, no hay que perder de vista el horizonte de la época en que se inscribe la tensión que analizamos en este trabajo, pues es un hecho que uno de los motivos principales de la crisis de la polis fue la emergencia de los intereses privados en detrimento de la idea del bien común, cuestión que se refleja en la crítica aristotélica a la crematística, como demostraremos más adelante.

Por lo dicho es insoslayable, y acaso imposible, que en la comprensión y caracterización de la política no se implique un modo de relación con la dimensión económica. Nuestro artículo se propone indagar y problematizar un modo específico de relación entre ambas esferas. Nos referimos al que sostiene que la condición de posibilidad de la política consiste en trazar un límite infranqueable entre ella y la dimensión económica. Esta visión, que hace énfasis en la necesidad irremediable de separar la política de la economía, ha encontrado, como se sabe, una expresión paradigmática en el pensamiento de Hannah Arendt. El camino que encontró la pensadora alemana para fundamentar dicha separación fue el de un retorno al pensamiento político de Aristóteles, en particular a los parágrafos que componen el magistral libro I de la Política. Allí, Aristóteles examina y caracteriza el oíkos y la polis como dos formas específicas de comunidad irreductibles la una a la otra a causa del distinto fin que les es inherente. Mientras al oíkos le corresponde el telos del vivir, a la polis le concierne el vivir bien.

Ahora bien, esta división tajante entre ambas dimensiones, claramente expuesta en el libro I y aceptada por Arendt, resulta como mínimo matizada a la luz del análisis y la caracterización de los regímenes políticos de la democracia, la oligarquía y la politeia. Especialmente en el libro IV de la Política, Aristóteles incluye la economía como una dimensión que particulariza los regímenes políticos, es decir, que determina su forma específica de ser. Así, por dar un ejemplo, vemos que la caracterización del sujeto político es una caracterización de carácter económico: en la democracia, el sujeto político son los libres-pobres, en la oligarquía los ricos y en la politeia los que poseen una propiedad media.

A la luz de los aspectos que componen la mirada y la caracterización aristotélica de los regímenes políticos, nuestro artículo se propone contribuir a mostrar que la relación entre economía y política puede pensarse de un modo diferente al legado hermenéutico que Arendt construye a partir del pensamiento político aristotélico, es decir, un modo

but it causes harm so there had better be an unacceptable use of it."] S. Meikle, "Aristotle on Money", Phronesis, vol. 39, 1994, pp. 26-44; la cita es de la p. 39. 
en el que la economía y la política, lejos de ser mutuamente excluyentes, se muestran en su irremediable compenetración. Nuestra propuesta consiste en reflexionar acerca de los modos en los que la política y la economía se articulan en la cosmovisión aristotélica. Para ello, trabajaremos dos ejes temáticos. En primer lugar, la relación entre oíkos y polis y, en segundo lugar, la relación entre economía y los regímenes políticos.

\section{La relación entre oikonomía y polis en el pensamiento de Aristóteles}

La economía se interpretó de manera paulatina en la Modernidad como una esfera autónoma y se relacionó con el desarrollo de la técnica. Con ello perdió su vinculación con la ética. Recordemos que, para Aristóteles, tal escisión no existía, ${ }^{5}$ y que incluso el propio Adam Smith se consideraba en su propio contexto un filósofo moral. ${ }^{6}$ En lo que atañe a la autonomización de la economía, la siguiente observación de Charles Taylor es sugerente: "La economía fue tal vez la primera dimensión de la sociedad civil que alcanzó una identidad independiente de la política."7

Por otro lado, para el mundo griego el conocimiento no estaba escindido de la noción de areté, que se encarnaba en las dotes singulares de cada habitante de la polis. En tal cosmovisión subyace el supuesto según el cual ningún ciudadano puede realizarse si no lo hace la comunidad política. No hay que perder de vista que Aristóteles postuló la categoría de autarquía como característica constitutiva de la polis. Así, la propia pertenencia a la polis es el sustrato a partir del cual podían desarrollarse las diferentes capacidades, a través de la educación. ${ }^{8}$

${ }^{5}$ Tal como observa M. Riedel, el pensamiento político del idealismo alemán hace suya la visión aristotélica respecto del vínculo entre la economía y la política con el fin de realizar una crítica a los nuevos principios introducidos por la economía moderna, donde la politicidad es socavada por las fuerzas económicas individualistas. Cfr. M. Riedel, Metafísica y metapolítica. Estudios sobre Aristóteles y el lenguaje político de la filosofía moderna, trad. E. Garzón Valdés, Alfa, Buenos Aires, 1976.

${ }^{6}$ Sobre esta cuestión, véase A. Sen, Sobre ética y economía, trad. Á. Conde, Alianza, Madrid, 2008.

${ }^{7}$ Ch. Taylor, Imaginarios sociales modernos, trad. R. Vilà Vernis, Paidós, Barcelona, 2006, p. 104.

${ }^{8} \mathrm{Al}$ respecto son relevantes las hermenéuticas de A. Sen y M. Nussbaum que, inspirados en Aristóteles, profundizaron en una teoría de las capacidades y las virtudes en relación con la vida buena en la escena contemporánea. Cfr. Sen, Sobre ética y economía, op. cit.; M. Nussbaum, La fragilidad del bien: fortuna y ética en la tragedia y la filosofía griega, trad. A. Ballesteros, Visor, Madrid, 1995. 
En esta misma dirección se desarrolló la perspectiva de Arendt, en tanto que esta pensadora manifestó que hubo que esperar al desarrollo y a la autonomía de la sociedad civil, como mundo de lo privado, para que la economía se constituyera como ciencia. De acuerdo con Arendt:

[N]os resulta difícil comprender que, según el pensamiento antiguo sobre estas materias, la expresión economía política habría sido una contradicción de términos: cualquier cosa que fuera económica, en relación a la vida del individuo y a la supervivencia de la especie, era no política, se trataba por definición de un asunto familiar. ${ }^{9}$

Esta apreciación reviste gran interés porque, independientemente de que Arendt no haya acuñado el término biopolítica, es evidente que sí fue una de las precursoras de quienes se han dedicado a pensar en esa cuestión. ${ }^{10}$

La vinculación entre economía y supervivencia —ambas instancias colocadas en la esfera doméstica y ligadas al terreno de la necesidad y no de la libertad - da cuenta clara de la transformación que provocó el surgimiento de la Modernidad, donde la supervivencia pasó a ser el objeto central de la política. Por ende, el tema de la vida, en su sentido más biológico, ingresa, ahora, a la escena pública. Ésta es una de las razones por las que Arendt ha argumentado que sólo en la necesidad hay coerción, a la que un griego jamás hubiese ubicado en el espacio público pues — como espacio de la libertad- éste no podría jamás estructurarse desde la impronta de la necesidad y la violencia. Es

\footnotetext{
${ }^{9}$ H. Arendt, La condición humana, trad. R. Gil Novales, Paidós, Buenos Aires, 2003, p. 42.

${ }^{10}$ Quien utilizó por primera vez la expresión "biopolítica" fue Michel Foucault (las referencias más importantes se encuentran en Historia de la sexualidad I. La voluntad del saber, trad. U. Guiñaz, Siglo XXI, Buenos Aires, 2002; Seguridad, territorio y población, trad. H. Pons, Fondo de Cultura Económica, Buenos Aires, 2006; Nacimiento de la biopolítica, trad. H. Pons, Fondo de Cultura Económica, Buenos Aires, 2007). Este término se refiere a la implicación de la vida biológica del hombre en los mecanismos y dispositivos del poder. El pensador que ha hecho célebre la cuestión biopolítica en las últimas décadas ha sido Giorgio Agamben (fundamentalmente en Homo sacer I. El poder soberano y la nuda vida, trad. A. Gimeno Cuspeira, Pre-Textos, Valencia, 1999), quien ha tomado el vocablo foucaultiano y lo ha cargado con muchos de los conceptos utilizados por Arendt. Así, la diferencia entre Foucault y Agamben es que, para este útlimo, la biopolítica existe siempre que se conciba a la política como atributo, como excepción; por ello, para el filósofo italiano, la característica distintiva de la política moderna es la coincidencia entre excepción y norma y no la inclusión de la vida biológica en la política (a la que habría pertenecido todo el tiempo).
} 
por ello que interpretamos que, no de manera casual, la definición del Estado moderno por excelencia ha sido la de monopolio organizado de la coerción. ${ }^{11}$ Sin embargo, incurriríamos en un error si pensáramos la libertad en la polis griega con la categoría de "libre arbitrio" que emerge en el universo judeocristiano ${ }^{12}$ pues, para un griego, la libertad estaba vinculada a la autoproducción de leyes a las que la propia comunidad política se sometía.

Aristóteles es muy claro cuando señala que la economía, como techné del oíkos, debe subordinarse a la política, pues el fin de ésta no es el vivir — como mera subsistencia biológica-, sino "el buen vivir" (relacionado con la felicidad y el telos de la vida humana), que supone necesariamente al primero. Así, resulta insoslayable apuntar que, para Aristóteles, ambas dimensiones (la del oíkos y la subsistencia, por un lado, y la de la política y la realización, por el otro) no son mutuamente excluyentes, sino que son complementarias. ${ }^{13}$ Es por ello que la política indica la dirección y el fin de la economía, y Aristóteles es categórico al sostener que el buen vivir, propio de la polis, supone tener resueltas las necesidades de la alimentación, la reproducción, la educación, la religión y todas las dimensiones que se resuelven en el espacio del oíkos.

${ }^{11}$ Es importante recalcar que, en este sentido, hay una coincidencia incluso entre perspectivas teóricas divergentes. Las definiciones de la izquierda y del liberalismo del Estado han coincidido en resaltar sobre todo su carácter de portador monopólico de la fuerza física legítima. Cfr. M. Weber, "La política como vocación", El político y el científico, trad. F. Rubio Llorente, Alianza, Madrid, 1998, pp. 81-179; V. Lenin, El Estado y la revolución, trad. J. de Andrés, Alianza, Madrid, 2006.

${ }^{12}$ Dicha cuestión irrumpe con fuerza en el cristianismo como portador del principio de la subjetividad, para decirlo en términos hegelianos. En otros términos, lo más importante para un cristiano es su salvación individual, que se jugará en una dimensión ontológico-existencial, en relación con su voluntad, como sede del libre arbitrio y orientada a elegir bienes trascendentales o bienes terrenales. Al respecto, Agustín de Hipona es un reflejo fiel de lo dicho. Desde esta misma perspectiva, son sugerentes las referencias de Arendt en relación con Agustín de Hipona cuando recrea la sentencia agustiniana "me he convertido en una preocupación para mí mismo" (Arendt, La vida del espíritu, trad. C. Corral, Paidós, Barcelona, 2002), cuestión que es más que ajena al universo de la polis griega.

${ }^{13}$ En Mito y sociedad en la Grecia antigua (trad. C. Gázquez, Siglo XXI, Madrid, 2003, pp. 5-20), Jean Pierre Vernant indaga sobre los diferentes modos de relación entre economía y política en la antigua Grecia a fin de mostrar que esos ámbitos obedecieron a la variedad de prácticas agrupadas con el término oikonomía: 1) como técnica reducida a la producción agrícola, 2) como técnica orientada al crecimiento de la ciudad y 3) como gran comercio exterior orientado al beneficio personal.

Diánoia, vol. LIX, no. 73 (noviembre de 2014). 
Por lo anterior, discordamos en este aspecto con la hermenéutica arendtiana, pues no percibimos una relación dicotómica entre el ámbito del oíkos y el ámbito político. Así, resulta más comprensible por qué una de las reformas más importantes de la Atenas democrática haya sido la introducción del sueldo (misthós) para aquellos que ocuparan cargos públicos, como un modo de resolver sus necesidades domésticas y pensado estrictamente para los estamentos medios, vinculados generalmente a la falta de libertad económica completa.

Sin embargo, la visión de Arendt tiene su razón de ser, ya que ella percibe de manera nítida el problema histórico que provoca en el universo griego la tensión entre la política y la economía. En tal sentido, podemos observar el carácter prescriptivo que supone el pensamiento de Aristóteles en lo que se refiere a la subordinación de la economía a la política. Asimismo, es relevante puntualizar la contraposición entre el Mundo Antiguo y el Mundo Moderno en lo que respecta a pensar el objetivo de la política, ahora del lado de la vida (en su sentido más biológico), olvidando el ideal aristotélico de la buena vida (a lo sumo relegado en la Modernidad al ámbito de lo privado). A modo de ejemplo, basta con traer a colación la construcción teórico-política hobbesiana. En ésta, el fundamento del contrato realizado por voluntades individuales tiene por meta primordial la salida de un estado de naturaleza que se caracteriza en términos de una guerra potencial de todos contra todos. Así, se devela que el objetivo primario de la política es la preservación de la vida en su sentido biológico, lo que en términos aristotélicos equivaldría al ámbito de la mera vida. ${ }^{14}$ Sin lugar a dudas, la hermenéutica arendtiana, sobre todo en su célebre texto $L a$ condición humana, hace énfasis en las contraposiciones vida/buen vivir, necesidad/libertad, seguridad/felicidad para explicitar la inversión de sentidos que sufre la política en la Modernidad. Sin embargo, si bien no puede dudarse de esas contraposiciones, Arendt omite ciertos puntos en común entre Hobbes y Aristóteles, como es el caso de la subordinación de la economía a la decisión política. Con todo, es insoslayable señalar

\footnotetext{
${ }^{14}$ Sobre esta cuestión es interesante la distinción de Agamben, aplicada al mundo griego, entre bíos y zoé, para resaltar que el interés de los griegos es en la forma de vida y no en la pura biología. Sin embargo, nosotros creemos que, para Aristóteles, aun la vida biológica del hombre es diferente a la del animal, más allá de que compartan la definición por género. Una vez más, insistimos en que Aristóteles es un pensador armónico y, por lo tanto, no se juega en él la dicotomía entre vida biológica y forma de vida, aunque esta última implique una diferencia específica de lo humano que no puede encontrarse en un animal. Véase Agamben, Homo Sacer I, op. cit.
} 
que, en el caso hobbesiano, la decisión radica en la voluntad del soberano, mientras que, en el caso aristotélico, la decisión está mediada por la comunidad deliberativa.

Para Aristóteles, como veremos en las citas siguientes, la economía, lejos de colocarse en un punto antagónico a la política, aparece como tema de deliberación política, lo cual demuestra que el fundamento del buen vivir no puede dejar de lado la satisfacción de las necesidades vitales alcanzadas por una buena economía. Según Aristóteles:

Los principales temas sobre los que todo el mundo delibera y sobre los que hablan en público aquellos que dan consejos son, poco más o menos, en número de cinco. A saber: los que se refieren a la adquisición de recursos, a la guerra y a la paz, y, además, a la defensa del territorio, de las importaciones y exportaciones, y a la legislación. De ese modo, el que piense dar consejos sobre la adquisición de recursos convendrá que conozca cuáles y cuántas son las ganancias de la ciudad, a fin de, si alguna ha sido omitida, reponerla, y si alguna es escasa, aumentarla; y lo mismo la totalidad de los gastos, para eliminar el que sea superfluo y reducir el que sea excesivo. ${ }^{15}$

Asimismo, Aristóteles articula de un modo claro que la complementariedad de la economía y la política se expresa en la necesidad de que la comunidad deliberativa tome en cuenta, contemple como uno de sus sentidos, los intereses de los ciudadanos que se dedican al comercio. Por ello, Aristóteles advierte que:

Por lo que toca a las provisiones, se debe conocer cuántos y cuáles gastos son suficientes para la ciudad, qué es lo que ella produce por sí misma y lo que importa y qué artículos de exportación e importación precisan otros pueblos, a fin de suscribir con ellos acuerdos y pactos. En este sentido, es menester vigilar con cuidado que estén libres de queja los ciudadanos correspondientes a dos tipos: los más fuertes y los que son útiles para el comercio. $^{16}$

Estas dos citas muestran con nitidez cómo las necesidades materiales de la polis son también un tema de deliberación indispensable en la esfera pública. También se ve claramente la imbricación mutua entre oíkos y polis. En tal sentido, coincidimos con la óptica de Carlo Natali, quien sostiene que:

${ }^{15}$ Aristóteles, Retórica 1359b 20-28 (trad. Q. Racionero, Gredos, Madrid, 1982).

${ }^{16}$ Política 1360a 12-18. Acerca de la concepción aristotélica de la oikonomía en relación con la riqueza, véase Política 1335a; y Ética nicomáquea 1094a. 
Aristóteles es el autor en el que confluyen todas las diversas acepciones de oikonomía, aquellas ligadas al uso corriente y aquellas más normativas, definidas con base en los principios de la política y de la filosofía práctica. Da cada una de las definiciones ex professo acerca de qué es la ciencia económica, pero al mismo tiempo se sirve del concepto de oikonomía en el modo más próximo al uso común. ${ }^{17}$

La obra principal en la que Arendt planteó la dicotomía entre economía y política (nos referimos, por supuesto, a La condición humana) reclama para sí un patrocinio aristotélico al diferenciar el ámbito de la labor y el trabajo del de la acción. Sin embargo, sus concepciones se basan en una interpretación errónea de los textos de Aristóteles, en tanto que les aplica parámetros modernos y absolutamente abstractos. Arendt deduce sus conceptos de una idea de polis muchas veces idealizada y romántica, que no toma en cuenta las distintas circunstancias histórico-materiales y que separa la vida griega en dos espacios irreconciliables. La filósofa estaba preocupada principalmente por los peligros de la guerra, cuestión que la hizo pensar (y con razón) que la política podía perder su autonomía y sus capacidades creativas (o incluso desaparecer del mundo). En ese sentido, la oposición entre "público" y "privado" era eficaz para comprender el paso del hombre al ciudadano, y el pretendido quiebre absoluto entre la violencia y la desigualdad del oíkos y la igualdad ante la ley del ámbito político (regulado por la palabra). ${ }^{18}$ Con ello, Arendt sustentó una tesis cuyo fin era develar, y a la vez denunciar, el triunfo de la lógica privada sobre la pública en todos los niveles de la vida moderna.

Sin embargo, perder de vista la relación íntima entre ambas esferas, su complementariedad y continuidad casi absolutas, no es válido si se pretende (como en nuestro caso) comprender el pensamiento aristotélico en su propio contexto y solamente desde allí establecer el diálogo con la realidad actual. Al contrario de lo que afirma la pensadora alemana, cabría decir que, si la división entre "lo público" y "lo privado" en la Modernidad es difícil de hallar (como ella misma lo expresa), ${ }^{19}$ extrapolar tal distinción a la Antigüedad (y al pensamiento aristotélico) es aún más complicado.

${ }^{17}$ C. Natali, "Introduzione", en Pseudo-Aristóteles, L'amministrazione della casa, Laterza, Roma, 1995, p. 24.

${ }^{18}$ Para una mayor profundización en estas cuestiones, véase A. Heller, Aristóteles y el mundo antiguo, trad. J.-F. Yvaras, Península, Barcelona, 1983.

${ }^{19}$ Arendt, La condición humana, op. cit., p. 46. 
Asimismo, y más allá de lo enunciado directamente por Arendt, la postura liberal acerca de las mencionadas esferas ha reestructurado a tal punto los elementos de cada una de ellas que ha colocado en la "esfera privada" aspectos tales como la libertad de creencias y opiniones, la postura política, la propiedad privada y el derecho a la intimidad en relación con la información sobre el patrimonio. Todos estos elementos pertenecían en el universo aristotélico al ámbito de lo político, dado que, como vemos, la continuidad entre oíkos y polis era inmensamente mayor que lo que la mayoría de los autores modernos han querido aceptar.

Al respecto, una erudita nos explica que los términos arcaicos que definían lo público y lo privado no eran tan categóricos como en la Modernidad:

$\mathrm{El}$ adjetivo idios se refiere a lo que es privado, a las cosas que pertenecen particularmente a uno. Puede describir intereses privados o de la casa, propiedad privada, viviendas privadas, conversaciones privadas entre individuos [...]. El sustantivo demos originariamente se refería a un distrito del campo habitado por plebeyos para distinguirlo de las ciudades ocupadas por los líderes políticos. Más tarde pasó a representar a la gente común y, en las constituciones democráticas, al orden constituido de ciudadanos [...]. Idios se opone también a koinos, que, de modo similar, denota lo que es compartido en las relaciones sociales entre amigos o en la actividad política en el ámbito público. Koinos puede también denotar parentesco, cortesía e incluso imparcialidad. Unido a agathos significa el "bien común". ${ }^{20}$

Es fundamental aclarar además que, si bien Aristóteles consideraba la política la acción más excelente en el nivel social, ésta no constituía el único factor de cohesión de las comunidades de las poleis griegas. Como el propio Estagirita lo explica, históricamente la polis es producto del desarrollo del oíkos y de la aldea debido a la falta de autarquía que ambas formaciones presentaban. ${ }^{21}$ En otras palabras, lo que le otorgaba su naturalidad a la política (y al hombre su carácter de zoon politikón) era que sólo en el ámbito de la polis, en el que cada uno compartía la vida con los demás, los hombres hallaban su realización, es decir, alcanzaban su telos y, por ende, lógicamente, eran fieles a su phýsis. Pero ello no restaba en nada la gran importancia del oíkos como espacio formativo y necesario para la política.

${ }^{20}$ S. Wiltshire, Public and Private in Vergil's Aeneid, University of Massachusetts Press, Amherst, 1989, p. 9.

${ }^{21}$ Política $1252 \mathrm{~b}$.

Diánoia, vol. LIX, no. 73 (noviembre de 2014). 
Si volvemos a un asunto que mencionábamos al principio de este artículo, podemos afirmar que la subordinación de la economía a la política atiende dos aspectos complementarios: el de la política como práxis que, como esfera de la deliberación, debe direccionar los recursos de la economía en función del interés colectivo, y el de la política como ciencia principal a la que se subordina la economía. ${ }^{22}$

Parecería que ha de ser la suprema y directiva en grado sumo. Ésta es, manifiestamente la política. En efecto, ella es la que regula qué ciencias son necesarias en las ciudades y cuáles ha de aprender cada uno y hasta qué extremo. Vemos, además, que las facultades más estimadas le están subordinadas, como la estrategia, la economía, la retórica. Y puesto que la política se sirve de las demás ciencias y prescribe, además, qué se debe hacer y qué se debe evitar, el fin de ella incluiría los fines de las demás ciencias, de modo que constituiría el bien del hombre. ${ }^{23}$

No deja de ser interesante adoptar una dimensión analítica de la política en lo que atañe a alojar estas disciplinas o artes, sin las cuales ella devendría mera abstracción. La mención de la estrategia puntualiza el hecho de que en la Antigüedad la guerra formaba parte cotidiana de la política. Por su parte, la retórica se asienta en uno de los aspectos nodales del logos como elemento de la persuasión que, a diferencia de los sofistas, no se vincula con el engaño, pues acepta el presupuesto de la razón como zócalo común; esto también refuerza una racionalidad afectiva como base. ${ }^{24}$

En pocas palabras, y tal como dijimos anteriormente, el oíkos y la polis eran dos especies de comunidad cuyo vínculo se caracterizaba por la continuidad y no por la contradicción. Mientras que la segunda se tenía como la esfera en la que se daba efectivamente la realización humana, los elementos que constituían el oíkos en la Grecia antigua eran, principalmente, la educación, las regulaciones religiosas, la familia extendida y el derecho de propiedad. Es decir, el oíkos se concebía y habitaba no como espacio en el que los hombres alcanzaban su realización, sino el que los disponía directamente hacia ella.

Sobre esta cuestión podemos referirnos al extenso trabajo de Brendan Nagle acerca del oíkos como base fundamental de la política en

${ }^{22}$ Cfr. M.A. Rossi y P. Tierno, "A dimensão econômica da teoria politica aristotelica", Lua Nova, vol. 77, 2009, pp. 179-204.

${ }^{23}$ Ética nicomáquea 1094a 1-1094b 6.

${ }^{24}$ Sobre esta cuestión resulta muy apropiada la lectura de E. Berti, Las razones de Aristóteles, trad. H.A. Gianneschi, Oinos, Buenos Aires, 2008. 
el pensamiento aristotélico. En él, Nagle demuestra de manera contundente la funcionalidad de los hogares griegos como componentes inherentes de las ciudades, en los cuales se realizaban la producción, reproducción y educación que formaría a los ciudadanos. ${ }^{25}$ Así, la introyección del nomos político no hubiese sido posible sin la existencia de esta institución.

Hasta aquí hemos expuesto las derivas teóricas de Aristóteles en relación con el vínculo entre la polis (el todo) y el oíkos (la parte). Si bien este análisis es fundamental para comprender su perspectiva política, no podemos dejar de lado una lectura profunda sobre el modo concreto en el que el Estagirita concibió la relación entre las formas de gobierno y los usos de la oikonomía en pos de una arquitectura política que apunte a la buena vida.

\section{Una lectura económica de los regímenes políticos}

En lo que respecta a anclar la economía en el terreno doméstico en el pensamiento de Aristóteles, la hermenéutica de Arendt ha contribuido a que los estudios posteriores descuidaran los diferentes matices y usos que el Estagirita emplea en relación con la categoría de economía, pues si bien es más que importante situar a la economía en el ámbito doméstico, no es menos cierto que Aristóteles traspasa dichos umbrales a la hora de abordar los regímenes políticos. Por ello, intentaremos mostrar cómo el terreno de la economía no puede desvincularse del problema real de la democracia, de la oligarquía y de la politeia.

La mejor forma de demostrar que Aristóteles sostiene que la polis y el oíkos son complementarios es tomar en cuenta que, a la hora de esbozar su mejor régimen posible, la politeia, el Estagirita considera que la cuestión económica es un aspecto fundamental de tal forma de gobierno. ${ }^{26}$ Por ende, es el primero en la historia de Occidente en vincular los regímenes políticos con la estructura socioeconómica de la polis.

El objetivo de este apartado será, entonces, explicitar los problemas concretos que Aristóteles encuentra en la oligarquía y en la democra-

${ }^{25}$ B. Nagle, The Household as the Foundation of Aristotle's Polis, Cambridge University Press, Nueva York, 2006, p. 8.

${ }^{26}$ En la Política (1294b), Aristóteles utiliza la fórmula del término medio entre un exceso y un defecto propia de la virtud para proponer a la clase media como sujeto ciudadano de la politeia: "Por ejemplo, las democracias no exigen propiedad alguna, o muy pequeña, para participar de la asamblea; las oligarquías exigen una gran propiedad. El término común no será ni uno ni otro, sino el medio entre ambas propiedades." 
cia al considerarlos regímenes políticos desviados. En este aspecto en particular se percibe cómo cuando la crematística es de carácter antinatural, la administración de la casa se hace imposible. De esta manera, la diferencia entre oíkos y polis se desvanece, con la consecuencia de que aparece una intromisión plena de la lógica acumulativa en la actividad política.

En el libro IV de la Política, Aristóteles analiza los regímenes políticos de la democracia y la oligarquía para determinar sus rasgos específicos y caracterizar sus distintas variantes. En el transcurso de este análisis señala que la diferencia cuantitativa (muchos-pocos) no puede constituir la distinción de carácter cualitativo que está buscando: "No se debe considerar democracia, como suelen hacer algunos en la actualidad, simplemente donde la multitud es soberana [...]; ni tampoco oligarquía donde unos pocos ejercen la soberanía del régimen". ${ }^{27}$

La afirmación de que en la democracia los ciudadanos que participan en las magistraturas son muchos, mientras que en la oligarquía son pocos es, según Aristóteles, una verdad de hecho, pero no una verdad con carácter necesario. Es decir, podría darse el caso - poco usual, por cierto- de que una oligarquía tuviera una ciudadanía amplia y una democracia, por el contrario, una de carácter restringido, y eso no obstaría para que ambos continuaran siendo regímenes bien definidos. Por ello, la diferencia entre ellos y sus cualidades específicas sólo puede ser del orden de la cualidad. En palabras de Aristóteles, "existe democracia cuando los libres ejercen la soberanía, y oligarquía cuando la ejercen los ricos". ${ }^{28} \mathrm{Si}$ algunos de los atributos que Aristóteles asigna a ambas ciudadanías pueden ser complementarios, está claro que esto no sucede con los de la riqueza y la pobreza. En ellos no sólo se enuncia la diferencia entre la ciudadanía oligárquica y la democrática, sino que, en igual medida, se expresa la oposición irremediable entre sus respectivos principios de constitución de la ciudadanía. Mientras que en la democracia los ricos quedan sometidos a la regla de la mayoría (los pobres), en la oligarquía los pobres están excluidos de la participación de las magistraturas. Dice Aristóteles al respecto: "Todos rivalizan en virtud y se creen capaces de desempeñar la mayoría de las magistraturas; pero es imposible que los mismos ciudadanos sean a la vez pobres y ricos." 29

Como podemos ver, Aristóteles afirma que en el principio de composición de la ciudadanía democrática y oligárquica se encuentra implícita

${ }^{27}$ Política, 1290a 30-35.

${ }^{28}$ Política, 1290b 1-2.

${ }^{29}$ Política, 1291b 19.

Diánoia, vol. LIX, no. 73 (noviembre de 2014). 
una verdadera aporía para la praxis, que reclama con acuciante necesidad una forma de organización política que la contemple y la resuelva. Mediante un verdadero gesto de ingeniería política - como la creación de una clase media para la existencia de la politeia-, Aristóteles consigue hallar una vía de solución.

Sin embargo, dicha respuesta aristotélica (por la mejor forma posible de gobierno) requiere que se visualice antes el trasfondo común entre la democracia y la oligarquía. Sólo así se puede comprender que la politeia sea el resultado de la suma de los aspectos positivos de ambos regímenes. Pero veamos la cuestión más de cerca: Aristóteles toma como criterios para definir al ciudadano democrático y al oligárquico la suficiencia o insuficiencia de propiedad con la que cuentan. A la insuficiencia de propiedad que caracteriza al ciudadano democrático se contrapone el exceso de propiedad que detenta el ciudadano oligárquico. Es en este modo negativo o positivo del tener en el que se expresan con claridad la diferencia y la oposición irremediables entre ricos y pobres. No obstante, esta diferencia no impide la existencia de aspectos comunes. La semejanza entre ambos se manifiesta en el hecho de que el sentido o la finalidad que alojan sus acciones resulta ser el mismo. Al respecto, dice Richard Mulgan:

Visto más de cerca, las diferencias entre los motivos perseguidos por los oligarcas y los demócratas son menores que las similitudes. Ambos buscan el beneficio material [...] Aristóteles se refiere a los motivos económicos de los que sostienen la democracia y arguye que éstos persiguen su propio beneficio en igual medida en que lo hacen los oligarcas. De hecho, en contraste con la nobleza, la mayoría de ellos se interesa más en el beneficio económico que en el honor. ${ }^{30}$

El bien que persiguen las acciones de los ciudadanos de la aristocracia es el honor. Este bien, tal como Aristóteles lo indica en su Ética nicomáquea, es el que corresponde específicamente a la vida activa, ya que resulta del reconocimiento que sólo puede darse entre los hombres libres e iguales que habitan el ámbito público: "En cambio, los mejor dotados y los activos creen que el bien son los honores, pues tal es ordinariamente el fin de la vida política". ${ }^{31}$ Por el contrario, el beneficio material es sinónimo de exclusión de la politicidad, ya que cuando se persigue ese fin no se pone en juego una relación entre el ciudadano y

${ }^{30}$ R. Mulgan, "Aristotle on Oligarchy and Democracy", en D. Keyt y F. Miller (comps.), A Companion to Aristotle's Politics, Blackwell, Oxford, 1991, p. 320.

${ }^{31}$ Ética nicomáquea 1095b 22-24.

Diánoia, vol. LIX, no. 73 (noviembre de 2014). 
su comunidad, sino sólo una relación entre el hombre y las cosas. De este modo, ya sea por exceso de bienes materiales o por su carencia, tanto el ciudadano oligárquico como el democrático convierten la acción política en una mera práctica adquisitiva; es decir, hacen que la acción devenga techné; más precisamente, la convierten en crematística y, por ello, introducen en la dimensión pública un sentido que se relaciona esencialmente con el oíkos.

$\mathrm{Si}$, como vemos, la democracia y la oligarquía coinciden en el hecho de que el oíkos traspasa sus límites y hegemoniza los sentidos propios del espacio público, resulta ahora insoslayable profundizar en la comprensión y comparación de ambos regímenes a partir de determinar el modo concreto en el que dicha intromisión tiene lugar. Para dar cumplimiento a tal fin, abordaremos - aunque sea someramente- la caracterización que Aristóteles hace de la crematística natural o necesaria y de la antinatural o innecesaria.

Como ya dijimos, en el libro I de la Política Aristóteles define la crematística del siguiente modo: "una especie de arte adquisitivo es naturalmente parte de la economía: es lo que debe facilitar o bien procurar que exista el almacenamiento de aquellas cosas para la vida y útiles para la comunidad de una ciudad o de una casa". ${ }^{32}$ La crematística es entonces un tipo de techné subordinado a la economía, es decir, a la techné de la administración. De este modo, la economía configura el límite de la crematística, ya que el sentido de la adquisición de recursos materiales no puede ser otro que la administración. Ahora bien, sabemos que ésta no es la única forma de adquisición que existe, sino que hay otra cuyo sentido consiste en la acumulación ilimitada de bienes exteriores. A esta forma Aristóteles la denomina antinatural o innecesaria, ya que en ella se revelan las ansias ilimitadas de bienes exteriores que imposibilitan al oíkos cumplir con su finalidad específica de satisfacer el vivir. Pero, además, Aristóteles nota que el peligro tras este apetito sin límites radica en su capacidad de hegemonizar el deseo humano de modo tal que tanto las facultades como las virtudes devengan un mero medio, un craso instrumento, para la consecución de dinero. Dice Aristóteles:

[S]i no pueden procurárselo por medio de la crematística, lo intentan por otro medio, sirviéndose de todas sus facultades no de un modo natural. Lo propio de la valentía no es producir dinero, sino confianza; ni tampoco es lo propio del arte militar ni de la medicina, sino la victoria y la salud,

${ }^{32}$ Política 1256a 10-15.

Diánoia, vol. LIX, no. 73 (noviembre de 2014). 
respectivamente. Sin embargo, algunos convierten todas las facultades en crematísticas, como si ése fuera su fin. ${ }^{33}$

Como podemos ver, la crematística antinatural puede significar algo más que una mera techné adquisitiva y convertirse en una forma de corrupción directa de las virtudes y las ciencias que conciernen - si no exclusivamente, al menos de manera prominente- a la dimensión política.

Aristóteles también dice que dicha corrupción comienza cuando la crematística se muestra inadecuada o insuficiente para la consecución de dinero, es decir, cuando falla o no alcanza para realizar el fin mencionado. Si bien esto puede sucederles tanto a los propietarios como al pueblo libre y pobre, lo cierto es que, a diferencia de aquéllos, éstos carecen de propiedad y no pueden siquiera comenzar el ciclo correspondiente a la acumulación. El exceso y la carencia de propiedad se muestran nuevamente como una diferencia insoslayable entre el modo en el que la oligarquía y la democracia promueven la intromisión del oíkos en el ámbito público.

$\mathrm{Al}$ respecto, Aristóteles percibe con claridad que para el caso de la oligarquía lo que no existió, incluso desde la primera infancia, es justamente un modelo pedagógico mediante el cual, en una suerte de economía del goce, el aspecto irracional del alma se subordine al aspecto racional; por esa razón, Aristóteles sostiene que los niños oligarcas no quieren obedecer ni siquiera a sus maestros, y aquí se juega el arquetipo del poder despótico por excelencia. Por otro lado, quienes carecen de suficiencia material se ven degradados a tal punto que la única vía de solución para su inclusión en la vida pública es de carácter estrictamente político y no ya paidético. En todo caso, la paideia sólo puede funcionar una vez que estén saldadas las necesidades básicas. Nadie mejor que el propio Aristóteles para dar fuerza a este argumento:

Por otra parte, los que están provistos en exceso de los bienes de la fortuna, fuerza, riqueza, amigos y otros semejantes, no quieren ni saben ser mandados, y esto les ocurre ya en casa de sus padres siendo niños, pues a causa del lujo en el que viven, ni siquiera en la escuela están acostumbrados a obedecer, mientras los que están en una indigencia excesiva están degradados; de modo que los unos no saben mandar, sino sólo obedecer a una autoridad propia de esclavos, y los otros no saben obedecer a ninguna clase de autoridad, sino sólo ejercer ellos una autoridad despótica;

${ }^{33}$ Política 1258a 17-20.

Diánoia, vol. LIX, no. 73 (noviembre de 2014). 
la consecuencia es una ciudad de esclavos y de amos, pero no de hombres libres. $^{34}$

Atendamos una contextualización que nos permita profundizar en la comprensión de esta cita. El advenimiento de la democracia a partir del siglo $\mathrm{V}$ a.E.C. implicó que el acceso a la ciudadanía comenzara a restringirse cada vez menos. Frente al ciudadano propietario y poseedor de todos los derechos emergió en la escena pública el hombre libre que, sin propiedad alguna, se encontraba destinado a trabajar; es decir, existían dos criterios de clasificación del hombre público que se entrecruzaban: por un lado, el goce o no del derecho de ciudadanía (hombre libre, meteco, esclavo) y, por otro, una gradación censitaria. Aristóteles contempla ambas dimensiones, tanto para caracterizar al ciudadano de la democracia y de la oligarquía, como para plantear la exclusión de la ciudadanía de aquellos que no cuenten con la propiedad suficiente para estar exentos de ocupar su tiempo en la realización de labores necesarias.

Está claro que la valoración que Aristóteles hace del trabajador se encuentra impregnada por una cosmovisión de la época en la cual la carencia de propiedad necesaria se considera un obstáculo insuperable para la práctica de la vida activa. Una vida ocupada en una crematística que nunca resulta satisfactoria, es decir, en una adquisición que no logra cumplir con su finalidad y no deja el tiempo libre necesario para hacerse cargo de los deberes ciudadanos es incompatible con la praxis política. En el libro III de su Política, Aristóteles es concluyente:

Realmente, ¿es ciudadano sólo el que puede participar del poder o también hay que considerar ciudadanos a los trabajadores manuales? [...] La

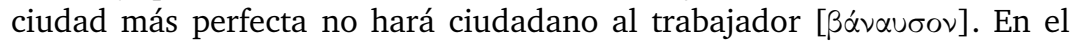
caso de que éste también sea ciudadano, la virtud del ciudadano de la que antes hablamos no habrá de aplicarse a todos, ni siquiera solamente al libre, sino a los que están exentos de los trabajos necesarios. ${ }^{35}$

Como vemos, a la incapacidad que tiene el obrero para la práctica de la virtud ciudadana se suma su semejanza con el esclavo. Esta semejanza es del orden de la cualidad y consiste en que ambos se dedican exclusivamente a la realización de los trabajos necesarios para la subsistencia. La diferencia entre ellos no resulta entonces ni de una comparación entre lo que son en sí y por sí, ni radica en lo que hacen. Lo único en lo que

\footnotetext{
${ }^{34}$ Política 1295b 15-25.

${ }^{35}$ Política 1278a 1-13.
} 
no coinciden es en quién es el que se beneficia con su trabajo, es decir, si éste es un amo o la comunidad. Así, el ciudadano de una democracia sin restricciones censitarias pareciera estar en el difuso límite entre ser y no ser libre. Esto resulta coherente con el hecho de que Aristóteles defina negativamente la libertad del ciudadano democrático. En sus propias palabras, la libertad democrática consiste en:

vivir como se quiere; pues dicen que esto es obra de la libertad, si precisamente es propio del esclavo vivir como no quiere. Éste es, pues, un segundo elemento definidor de la democracia, y de ahí vino el no ser gobernado preferentemente por nadie, y si no es posible, por turno. $Y$ de esta manera se contribuye a la libertad fundada en la igualdad. ${ }^{36}$

Las tres características que Aristóteles asigna a la democracia (vivir como se quiere, ${ }^{37}$ no ser gobernado por nadie y basar la libertad en la igualdad) muestran la dificultad que hay en ella para realizar una finalidad de carácter político. Esta dificultad se manifiesta claramente en la consecuencia que tiene la igualación de los distintos modos de vida, es decir, en la imposibilidad de la práctica de la virtud ciudadana. $\mathrm{Si}$, tal como señala Aristóteles, la virtud ciudadana consiste en que "el buen ciudadano debe saber y ser capaz de obedecer y mandar; y ésa

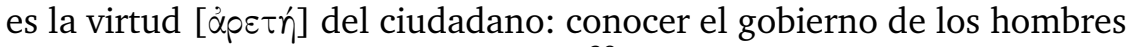
libres bajo sus dos aspectos a la vez", ${ }^{38}$ está claro que la eliminación de toda diferencia tiene como resultado el hecho de que en la democracia no pueda establecerse ni siquiera la diferencia entre gobernantes y gobernados. ${ }^{39}$

Así, vemos que la comprensión aristotélica de la oligarquía y la democracia está signada por una concepción determinada acerca de cuál es el límite natural que existe entre el oíkos y la polis. La diferencia específica de la democracia respecto de la oligarquía se origina, en última instancia, en que mientras que ésta expresa la intromisión del oíkos por exceso, aquélla lo hace por defecto.

${ }^{36}$ Política $1317 \mathrm{~b} 1-10$.

${ }^{37}$ La afirmación aristotélica que equipara la libertad democrática con el "vivir como se quiera" debe comprenderse en términos de una transgresión a la jerarquía de los distintos modos de vida (vida encaminada a la consecución de placeres, vida política y vida contemplativa). Véase Aristóteles, Ética nicomáquea, en especial el libro I.

${ }^{38}$ Política 1277b 13-16.

${ }^{39}$ En todo caso, la introducción del sorteo como forma de elección de los magistrados marca justamente esta imposibilidad.

Diánoia, vol. LIX, no. 73 (noviembre de 2014). 
A manera de conclusión sólo resta reiterar que el sentido de nuestro artículo ha sido mostrar el modo en el que Aristóteles concibe la relación entre economía y política. La primera conclusión a la que arribamos consiste en afirmar que el vínculo entre oíkos y polis no tiene, como lo postula Arendt, un carácter esencialmente dicotómico, sino, por el contrario, complementario. La segunda conclusión consiste en sostener que es en los regímenes políticos desviados de la democracia y la oligarquía en los que, según Aristóteles, se anula la condición de posibilidad de tal complementariedad, ya que en ellos se desvanece el límite entre el oíkos y la polis.*

\section{BIBLIOGRAFÍA}

Agamben, G., Homo sacer I. El poder soberano y la nuda vida, trad. A. Gimeno Cuspeira, Pre-Textos, Valencia, 1999.

Arendt, H., La condición humana, trad. R. Gil Novales, Paidós, Buenos Aires, 2003.

—_ La vida del espíritu, trad. C. Corral, Paidós, Barcelona, 2002.

Aristóteles, Ética nicomáquea, trad. Q. Racionero, Gredos, Madrid, 1985.

— Retórica, trad. Q. Racionero, Gredos, Madrid, 1982.

— Política, trad. M. García Valdés, Gredos, Madrid, 1988.

Berti, E., Las razones de Aristóteles, trad. H.A. Gianneschi, Oinos, Buenos Aires, 2008.

Foucault, M., Historia de la sexualidad I. La voluntad del saber, trad. U. Guiñaz, Siglo XXI, Buenos Aires, 2002;

- Seguridad, territorio y población, trad. H. Pons, Fondo de Cultura Económica, Buenos Aires, 2006.

— - Nacimiento de la biopolítica, trad. H. Pons, Fondo de Cultura Económica, Buenos Aires, 2007.

Heller, A., Aristóteles y el mundo antiguo, trad. J.-F. Yvaras, Península, Barcelona, 1983.

Lenin, V., El Estado y la revolución, trad. J. de Andrés, Alianza, Madrid, 2006.

Meikle, S., "Aristotle on Money", Phronesis, vol. 39, 1994, pp. 26-44.

Moreau, J., "Aristote et la monnaie", Revue des Études Grecques, vol. 82, no. 2, 1969, pp. 349-364.

Mulgan, R., "Aristotle on Oligarchy and Democracy", en D. Keyt y F. Miller (comps.), A Companion to Aristotle's Politics, Blackwell, Oxford, 1991.

Nagle, B., The Household as the Foundation of Aristotle's Polis, Cambridge University Press, New York, 2006.

*Este artículo es resultado de nuestro proyecto de investigación titulado "Las metamorfosis del sujeto clásico y los efectos políticos en los pensamientos de Aristóteles, Agustín y Campanella", financiado por el Consejo Nacional de Investigaciones Científicas y Técnicas, PIP 11220090100794. 
Natali, C., "Introduzione", en Pseudo-Aristóteles, L'amministrazione della casa, Laterza, Roma, 1995.

Nussbaum, M., La fragilidad del bien: fortuna y ética en la tragedia y la filosofía griega, trad. A. Ballesteros, Visor, Madrid, 1995.

Polanyi, K., "Aristóteles descubre la economía", en K. Polanyi, C. Arensberg y H.W. Peason, Comercio y mercado en los imperios antiguos, trad. A. Nicolás y J. Martínez Alier, Labor, Barcelona, 1976, pp. 111-144.

Riedel, M., Metafísica y metapolítica. Estudios sobre Aristóteles y el lenguaje político de la filosofía moderna, trad. E. Garzón Valdés, Alfa, Buenos Aires, 1976.

Rossi, M.A. y P. Tierno, "A dimensão econômica da teoria politica aristotelica", Lua Nova, vol. 77, 2009, pp. 179-204.

Sen, A., Sobre ética y economía, trad. Á. Conde, Alianza, Madrid, 2008.

Taylor, Ch., Imaginarios sociales modernos, trad. R. Vilà Vernis, Paidós, Barcelona, 2006.

Vernant, J.P., Mito y sociedad en la Grecia antigua, trad. C. Gázquez, Siglo XXI, Madrid, 2003.

Weber, M., "La política como vocación", El político y el científico, trad. F. Rubio Llorente, Alianza, Madrid, 1998, pp. 81-179.

Wiltshire, S., Public and Private in Vergil's Aeneid, University of Massachusetts Press, Amherst, 1989.

Recibido el 11 de noviembre de 2013; aceptado el 8 de mayo de 2014. 


\title{
La metafísica modal de Leibniz: su fundamentación de la contingencia hacia 1686 y su concepción integral de madurez
}

\author{
MAXIMILIANO ESCOBAR VIRÉ \\ Universidad de Buenos Aires \\ Universidad Nacional de Quilmes \\ m_escobarvire@yahoo.com
}

Resumen: Si Dios es la razón suficiente del mundo, entonces parece seguirse que todos los eventos son consecuencia necesaria de un ser necesario. Para evadir esta conclusión, Leibniz formula en la década de 1670 una concepción modal que funda la contingencia en un rasgo lógico e intrínseco de las ideas de las cosas: la posibilidad de concebir la idea contraria sin contradicción. Hacia 1686, Leibniz complementa esta primera concepción con lo que considera su solución definitiva al problema de la contingencia: la teoría del análisis infinito. Sin embargo, en otros escritos de ese año, propone dos vías alternativas de fundamentación de la contingencia. Este trabajo sugiere que esa pluralidad de modelos explicativos converge en una concepción integral de las modalidades que subyace como trasfondo de la reflexión modal leibniziana.

Palabras clave: modalidades aléticas, necesitarismo, esencias, nociones de sustancias individuales, decretos divinos primitivos

\begin{abstract}
If God is the sufficient reason for this world, then it seems to follow that every event is a necessary consequence of a necessary being. In order to avoid this conclusion, Leibniz states, during the 1670's, a modal conception that grounds contingency on a logical feature which is intrinsic to the ideas of things: the possibility of conceiving the opposite idea without contradiction. Towards 1686, Leibniz complements this first conception with what he considered to be his definitive solution to the problem of contingency: the theory of infinite analysis. However, in other writings from the same year, he proposes two different ways to explain contingency. This paper suggests that this plurality of models converges in a global conception of modalities, which lies at the background of Leibniz's modal thought.
\end{abstract}

Key words: alethic modalities, necessitarianism, essences, notions of individual substances, primitive decrees of God

\section{Introducción}

En 1686 Leibniz declara haber resuelto una aporía en cuyo estudio había permanecido largo tiempo irresuelta: la diferencia entre proposiciones necesarias y contingentes. La solución planteada es la que se conoce como su teoría del análisis infinito. Con ella, Leibniz pretende haber alcanzado, a sus cuarenta años, la solución definitiva a lo que 